\title{
Costs and Cost-Effectiveness of the Meeting Centres Support Programme for People Living with Dementia and Carers in Italy, Poland and the UK: The MEETINGDEM Study
}

Henderson, Catherine, PhD, London School of Economics and Political Science, c.henderson@1se.ac.uk, Houghton Street, London WC2A 2AE, UK, T: $+44(0) 2079557247$

Rehill, Amritpal, MSc, London School of Economics and Political Science, a.s.rehill@1se.ac.uk, Houghton Street, London WC2A 2AE, UK, T: +44(0)2079554665

Brooker, Dawn, PhD, University of Worcester, d.brooker@worc.ac.uk St Johns Campus, Henwick Grove, Worcester WR2 6AJ, United Kingdom, T: +44(0)1905 85 5250

Evans, Simon, C., PhD, University of Worcester, simon.evans@worc.ac.uk, St Johns Campus, Henwick Grove, Worcester WR2 6AJ, United Kingdom, T: +44(0)1905 85 5250

Evans, Shirley, B., PhD, University of Worcester, shirley.evans@worc.ac.uk, St Johns Campus, Henwick Grove, Worcester WR2 6AJ, United Kingdom, T: +44(0)1905 85 5250

Bray, Jennifer, University of Worcester, j.bray@worc.ac.uk, St Johns Campus, Henwick Grove, Worcester WR2 6AJ, United Kingdom, T: +44(0)1905 855250 
Saibene, Francesca Lea, M.Sc., IRCCS Fondazione Don Carlo Gnocchi ONLUS, fsaibene@dongnocchi.it, Via Alfonso Capecelatro 66, 20148 Milano, Italy, T: +39$02 / 40308.844$

Scorolli, Claudia, PhD, University of Bologna, claudia.scorolli@,unibo.it, Viale Berti Pichat 5, 40127 Bologna, Italy, T: +390512091821

Szcześniak, Dorota, PhD, Wroclaw Medical University, dorota.szczesniak@umed.wroc.pl, Pasteura 10, 50-367, Wroclaw, Poland, T: $+48717841600$

d'Arma, Alessia, M.Sc., IRCCS Fondazione Don Carlo Gnocchi ONLUS, adarma@dongnocchi.it, Via Alfonso Capecelatro 66, 20148 Milano, Italy, T: +390240308436

Lion, Katarzyna, MSc, Griffith University, k.lion@griffith.edu.au, 170 Kessels Road Nathan, Queensland 4111, Australia, T: +61 737358440

Atkinson, Teresa, MSc, University of Worcester, t.atkinson@worc.ac.uk, St Johns Campus, Henwick Grove, Worcester WR2 6AJ, United Kingdom, T: +44(0)1905 85 5250 
Farina, Elisabetta, MD, PhD, IRCCS Fondazione Don Carlo Gnocchi ONLUS, efarina@dongnocchi.it, Via Alfonso Capecelatro 66, I-20148 Milano, Italy, T: +390240308280

Rymaszewska, Joanna, MD, PhD, Wroclaw Medical University, joanna.rymaszewska@umed.wroc.pl, Pasteura 10, 50-367, Wroclaw, Poland, T: $+48717841600$

Chattat, Rabih, MD, PhD, University of Bologna, rabih.chattat@unibo.it, Viale Berti Pichat 5, 40127 Bologna, Italy, T: +390512091821

Meiland, Franka, PhD, Amsterdam University Medical Centres, location VU University Medical Centre, fj.meiland@amsterdamumc.nl, De Boelelaan 1109, 1081 HV Amsterdam, The Netherlands, $\mathrm{T}+31-20-4448237$

Dröes, Rose-Marie, PhD, Amsterdam University Medical Centres, location VU University Medical Centre, rm.droes@amsterdamumc.nl, Oldenaller 1, 1081HJ Amsterdam, The Netherlands, $\mathrm{T}+31-20-7885454$

Knapp, Martin, PhD, London School of Economics and Political Science, m.knapp@1se.ac.uk, Houghton Street, London WC2A 2AE, UK, T: +44(0)2079556225

Corresponding author:

Henderson, Catherine, PhD, London School of Economics, c.henderson@1se.ac.uk, Houghton Street, London WC2A 2AE, UK, T: +44(0)2079557247 


\section{Funding}

MEETINGDEM (2014-17) is an EU Joint Programme - Neurodegenerative Disease

Research JPND_HC-559-018. The project is supported through the following funding organisations under the aegis of JPND: Italy, Ministry of Education and Ministry of Health; The Netherlands, ZonMw; Poland, NCBR; UK, ESRC Grant reference: ES/L00920X/1.

\section{Conflict of Interest}

The authors declare that they have no conflict of interest.

\section{Ethical approvals}

UK-Health Research Authority (REC reference: 15/WA/0232), Poland- Bioethical Committee of Wroclaw Medical University (acceptance number: KB-219/2015), ItalyEthical committee of the IRCCS Don Gnocchi Foundation Lombardy Region (acceptance number 6/18022015) and VU University medical centre ethics committee confirmation of 'non-medical research' (decision number: 2013/370).

\section{Data Availability Statement/ Data Accessibility Statement}

Author elects to not share data due to privacy/ethical restrictions. 


\title{
Costs and Cost-Effectiveness of the Meeting Centres Support Programme for People Living with Dementia in Italy, Poland and the UK: The MEETINGDEM Study
}

\begin{abstract}
We examined the costs and cost-effectiveness of the Meeting Centre Support Programme (MCSP) implemented and piloted in the UK, Poland and Italy, replicating the Dutch Meeting Centre model. Dutch Meeting Centres combine day services for people with dementia with carer support. Data were collected over 2015-2016 from MCSP and usual care (UC) participants (people with dementia-carer dyads) at baseline and 6 months. We examined participants' health and social care (HSC), and societal costs, including Meeting Centre (MC) attendances. Costs and outcomes in MCSP and UC groups were compared. Primary outcomes: Persons with dementia: quality-adjusted life years (EQ-5D-5L-derived); QOL-AD. DQoL was examined as a secondary outcome. Carers: Short Sense of Competence Questionnaire (SSCQ). Incremental costeffectiveness ratios (ICER) and cost-effectiveness acceptability curves were obtained by bootstrapping outcome and cost regression estimates. Eighty-three MCSP and 69 UC dyads were analysed. The 6-month cost of providing MCSP was $€ 4,703$; participants with dementia attended MC a mean of 45 times and carers 15 times. Including intervention costs, adjusted 6-month HSC costs were $€ 5,941$ higher in MCSP than in UC. From the HSC perspective: in terms of QALY, the probability of cost-effectiveness was zero over willingness-to-pay (WTP) ranging from $€ 0$ to $€ 350,000$. On QOL-AD, the probability of cost-effectiveness of MCSP was $50 \%$ at WTP of $€ 5,000$ for a onepoint increase. A one-point gain in the DQoL positive affect subscale had a probability of cost-effectiveness of $99 \%$ at WTP over $€ 8,000$. On SSCQ, no significant difference
\end{abstract}


was found between MCSP and UC. Evidence for cost-effectiveness of MCSP was mixed but suggests that it may be cost-effective in relation to gains in dementia-specific quality of life measures. MCs offer effective tailored post-diagnostic support services to both people with dementia and carers in a context where few evidence-based alternatives to formal home-based social services may be available.

Keywords: cost-effectiveness; dementia and cognitive disorders; post-diagnostic support; psychosocial interventions

\section{What is known about this topic and what this paper adds}

What is known about this topic:

- Day care for people with dementia may improve wellbeing and provide respite for carers; little evidence exists on cost-effectiveness of day care

- Replicating day care models may be difficult due to heterogeneity in service objectives and delivery

- Dutch Meeting Centres Support Programme (MCSP) reduces behavioural problems in people with dementia and increases feelings of carer competence. What this paper adds:

- Most people with dementia attended MC in England, Italy and Poland at least weekly.

- The hourly cost of MC attendance was twenty percent higher than generic UK day care.

- MCSP may be cost-effective when considering dementia-specific quality of life but not health-related quality of life or feelings of carer competence.

\section{Introduction}

An estimated 7.3 million people in Europe are living with dementia (Galeotti et al.,

2013). The condition imposes high costs on the funders of health and care services, people living with dementia and their families. For instance, in England the total cost of dementia is estimated at $£ 24.2$ billion (2015 prices), with unpaid care costs accounting for $42 \%$ of the total (Wittenberg et al., 2019). Family carers provide an enormous amount of care and support to people with dementia, yet support services for carers of 
people with dementia across Europe leave much to be desired. Over half of carers surveyed by Alzheimer Europe were unable to access services such as home or day care; a third dedicated 10 or more hours daily to providing care for someone with moderate dementia; and the majority paid for home and residential care (Alzheimer Europe, 2006, 2014). Better post-diagnostic support is therefore arguably needed for people with dementia in the early stages of the condition (Alzheimer Europe, 2014).

Day care services have traditionally contributed to the mix of publicly funded support services to people with dementia. International evidence suggests that day services may bring benefits to carers in the form of respite and to people with dementia in terms of greater wellbeing; however, such services are highly heterogeneous and have many service objectives, posing challenges for replication and generalisability (Fields, Anderson, \& Dabelko-Schoeny, 2014; Manthorpe \& Moriarty, 2014; Tretteteig, Vatne, \& Rokstad, 2016). Evidence is lacking on cost-effectiveness of day services (Fields et al., 2014; Knapp, Iemmi, \& Romeo, 2013).

The Dutch Meeting Centre Support Programme (MCSP) model features day services combined with carer support. Dutch Meeting Centres (MC) are based in community facilities promoting an informal, non-medicalised, friendly environment. This personcentred psychosocial approach, grounded in the adaptation-coping model (Dröes, 1991; Dröes, van der Roest, van Mierlo, \& Meiland, 2011), features a range of creative activities, emotion-oriented care and psychomotor therapy designed by and for MC members with mild-to-moderate dementia and their close carers. Studies documenting outcomes of MCSP have found positive effects on overall measures of behaviour, inactivity, non-social behaviour, depression and self-esteem, as well as delays to institutionalisation for people with dementia, and reduced carer burden and increased feelings of carer competence (Dröes, Breebaart, Meiland, Van Tilburg, \& Mellenbergh, 
2004; Dröes, Meiland, Schmitz, \& van Tilburg, 2004; Dröes, Meiland, Schmitz, \& Van Tilburg, 2006; Dröes, Meiland, Schmitz, \& Van Tilburg, 2011). The MCSP model was recently adaptively implemented in Italy, Poland and the United Kingdom in the JPNDMEETINGDEM project. We conducted an economic analysis as part of an evaluation of MCSP for people with dementia and carers in these countries (Brooker et al., 2018; Evans et al., 2020). This paper reports the costs and cost-effectiveness of MCSP for people living with dementia and their carers across Italy, Poland and England.

\section{Methods}

\section{Design, sample and setting}

A controlled pre-test - post-test study was conducted. The study set a target sample size of 150 dyads of people with dementia and their carers ( 75 per arm), assuming $15 \%$ attrition, giving $80 \%$ power to detect a mean difference in study outcomes between groups at the $5 \%$ significance level, equating to a moderate effect size (Cohen's $d=0.5$ ) (Brooker et al., 2018). Research teams recruited dyads from communities in Italy, Poland and England. The intervention group (MCSP) comprised people with dementia and carers attending one of nine MCs established within the MEETINGDEM project in 2015-2016 (Dröes et al., 2017). The control group comprised people on a comparable part of the dementia pathway receiving usual care (UC) in the same region as those receiving MCSP, but outside the MCSP catchment area. Both groups had access to the same range of health and social care services, which could include day care without carer support or only medical support (as in Poland and Italy).

Evaluation data were collected between May 2015 and December 2016. All participants received assessments via face-to-face interview at baseline and 6-month follow-up. Baseline assessments of MCSP participants were conducted within a month 
of the person with dementia joining the MC; follow-up assessments took place 6 months after the first assessment. The main target group was people with mild-to-moderate dementia, scoring 4-5 on the Global Deterioration Scale (GDS), but those with milder severity (e.g. mild cognitive impairment) and those with more severe dementia were also included within the analyses as some Meeting Centres allowed these people to participate. People with dementia (of any type) and of any age could be included in the study if they had a close carer (e.g. spouse, other relative or friend) who also agreed to participate.

All necessary ethical approvals were secured by research teams. These were: UK-Health Research Authority (REC reference: 15/WA/0232), Poland- Bioethical Committee of Wroclaw Medical University (acceptance number: KB-219/2015), ItalyEthical committee of the IRCCS Don Gnocchi Foundation Lombardy Region (acceptance number 6/18022015) and VU University medical centre ethics committee confirmation of 'non-medical research' (decision number: 2013/370).

\section{Economic evaluation}

The objective of the economic evaluation was to compare outcomes and costs of MCSP and usual care dyads at 6-month follow-up in order to examine the cost-effectiveness of MCSP. The evaluation took, first, a health and social care perspective considering all costs to health and social care service providers and, second, a broader 'societal' perspective also including costs incurred by carers (time spent providing care, lost employment and out-of-pocket payments related to providing care).

Costs

We included costs of care and support for people with dementia and carers in MCSP and UC groups. Using the Client Service Receipt Inventory (CSRI) (Beecham \& 
Knapp, 2001), we collected data on (i) health and social care services used by the person with dementia; and (ii) carer time spent (on care and support activities, lost employment) and out-of-pocket expenditure on taking the person with dementia to condition-related treatment appointments. These data were used, respectively, to calculate (i) health and social care costs of the person with dementia and (ii) societal costs of the dyad. The CSRI covered service use and costs of participants with dementia, as reported by carers, in the 3 months prior to interview. We also collected data from MC managers on participants with dementia's MC attendances and mode of travel to the MC; and carer attendances and time spent attending MCSPs. These data were used to calculate intervention costs. Data on carers' own health and social care use were not collected.

All service use items, apart from intervention-specific items such as MCSP attendances, were valued by applying relevant, nationally generalisable English unit costs (principally National Health Service (NHS) reference costs (Department of Health, 2013), PSSRU Unit Costs (Curtis, 2015) and Prescription Cost Analyses (Health and Social Care Information Centre, 2015)). Applying English unit costs provided consistency in comparing costs across countries. Corresponding Italian and Polish unit costs from published sources were not available for every service use item. Instead UK costs were adjusted by purchasing power parities (PPP) (cf. Jowett et al., 2009; Patel et al., 2013). Unit costs in GBP and PPP-adjusted Euros are given in online supplementary file 1, Table S1.1. Carers' time was valued based on opportunity costs (national minimum wage for each country, in domestic currencies) (L.. Curtis, 2012; Koopmanschap, van Exel, van den Berg, \& Brouwer, 2008). We used unit costs at 2015 prices where available; costs from publications in earlier years were uplifted using the Hospital \& Community Health Services Index (Curtis, 2015). Country-specific costs 
(UK-based unit costs, intervention costs, out-of-pocket travel and unpaid care) were adjusted using PPP weights (OECD, 2017). This enabled aggregation of comparable costs across countries. We used the following conversion rates: 1.09 for GBP, 0.426 for Polish zloty (PLN) and 1.031 for Italian Euro. All costs presented are expressed in PPPadjusted Euro, unless otherwise stated.

To establish unit costs of MCSP attendances, we collected centres' costs over the initial six months of operation (except for the final centre opening in July 2016, where the initial 4 months of operation costs were adjusted to approximate 6-month costs). Costs were calculated to approximate long-run marginal opportunity costs (Allen \& Beecham, 1993), hence start-up elements such as initial training for staff were excluded. Centre managers provided information on MC costs (in domestic currencies) of: regular staffing (employment on-costs, administration time), volunteer inputs (valued adopting opportunity costs), building and utilities, fixtures, day-to-day running costs, and ongoing staff training (excluding training prior to opening). Costs of fixtures and fittings were estimated at half the annuitised value at a discount rate of 3.5\% (HM Treasury, 2003). Building costs could not be provided by centre managers, as most centres did not pay market rent on buildings (most paying peppercorn rent, if any, to municipalities). To estimate MC building costs in Poland and Italy, the UK cost of purchasing a square metre of land was adjusted for differences in plot sizes and converted to PPP-adjusted Euros. Rebuild costs were discounted over the lifetime of an average building of 60 years (L. Curtis \& Burns, 2015).

MCs collected aggregate activity data on attendances by people with dementia and carers (monthly attendance figures; operating hours; typical duration of groups for carers). Cost per attendance for individuals with dementia and carers was calculated by pro-rating total costs (estimated from aggregate attendance and duration data) according 
to total hours of attendance for each group. Total intervention costs for people with dementia and for carers were divided by the respective number of attendances to estimate per-attendance cost for each group. We estimated dyadic costs of attending MCSP over 6 months from baseline interview by attaching per-attendance (unit) costs of persons with dementia and carers to participants' attendance data.

Category-level costs were added to give total cost per case. Cases were included where cost data were available for both dyad members.

\section{Outcome measures}

We considered two main outcomes for participants with dementia: dementiarelated quality of life as measured by the QOL-AD (Logsdon, Gibbons, McCurry, \& Teri, 2002) and quality-adjusted life years (QALY). We mapped responses to EQ-5D5L (Brooks, 1996; Herdman et al., 2011; Janssen et al., 2013) to EQ-5D-3L index scores (using the UK value set), as currently recommended by NICE (National Institute for Health and Care Excellence, 2018; van Hout et al., 2012); and then calculated QALY from EQ-5D-3L scores using the area-under-the-curve method, with linear interpolation between assessments. As a secondary outcome, we also examined dementia-related quality of life as measured by the DQoL subscales (Brod, Stewart, Sands, \& Walton, 1999). The QOL-AD and DQoL measures were designed to capture quality of life in dementia in different ways. We used the Short Sense of Competence Questionnaire (SSCQ) (Vernooij-Dassen et al., 1999) as a carer outcome.

\section{Analysis}

Incremental costs and outcomes were estimated by jointly bootstrapping coefficients on the group allocation variable from separate costs and outcomes regressions (regression equations are given in the Appendix). Twelve thousand bootstrap replications were 
produced to estimate bias-corrected confidence intervals of the estimates. Regression covariates were allocation, country and dementia severity (re-categorised into three levels, following Aries et al. (2010): no-to-mild (GDS $<=3$ ), moderate (GDS 4-5) and severe (GDS 6-7)). Regressions of outcome measures were adjusted for baseline outcome measure (utilities in the QALY regression); cost regressions were adjusted for baseline costs. Regression estimates were used to calculate incremental costeffectiveness ratios (ICER), the difference in adjusted mean costs between intervention and control groups over the follow-up period, divided by difference in adjusted mean effects. The ICER represents the additional cost of MCSP over usual care of achieving the additional benefit of MCSP. MCSP can be considered cost-effective compared to usual care if it is more effective and less costly than usual care. MCSP also can be considered cost-effective compared to usual care if it is both more effective and more costly and the societal payer (e.g. public sector purchaser) is willing to pay the additional cost in order to achieve the gain in outcome produced by MCSP. In other words, the ICER must be below the societal payer's 'willingness-to-pay' (WTP) threshold.

We calculated net monetary benefit (the societal WTP for a gain in outcome, minus the cost of achieving it (Drummond, Sculpher, Claxton, Stoddart, \& Torrance, 2015) from regression estimates. For a given WTP, net monetary benefit must be greater than zero so that the costs of achieving the benefit do not outweigh the monetary benefit. The probability that the ICER was less than the given WTP (so that net monetary benefit exceeded zero) was plotted against a range of WTP values to produce cost-effectiveness acceptability curves (CEAC) (Glick, 2007). CEACs illustrate the impact of sampling uncertainty around the point estimate of the ICER and demonstrate the degree of decision uncertainty associated with the analysis (Drummond et al., 2015). 
We use a 5\% significance level throughout. If either dyad member withdrew from the study, the case was excluded from analysis. All analyses were carried out using complete cases.

\section{Sensitivity analysis}

We examined three scenarios to test the impact of our unit cost assumptions: a 'maximum-capacity' scenario (exploring the unit costs of MCSP if as many people with dementia and carers as possible attended each centre/group session offered), an acrossthe-board 10\% reduction in centre costs (if centres could find modest savings in labour and premises expenditure) and a 75\% reduction in Polish health and social care unit costs (exploring our assumption that valuing Polish health and care services in UK unit costs converted to PPP-adjusted Euro accurately reflected those service costs in the Polish economy). We also examined the impact of valuing unpaid care at replacement cost (using hourly cost of a homecare worker) (Faria, Weatherly, \& van den Berg, 2012). Methods and results of these analyses are detailed in online supplementary file S2; these (see results section) were in line with the main analyses results.

\section{Missing data}

In calculating per-participant costs, if the service costs contributing to a cost category were missing, the category total was calculated as missing; if only some costs were missing from the category, these were treated as zeros and the case assigned the sum of available costs within that category (numbers of cases contributing resource use and costs data are given within the results). Pro-rating of missing items within each outcome measure was carried out according to the missing data rules for that instrument. 


\section{Results}

A total of 229 dyads were approached to join the study (Brooker et al., 2018). Overall, 87 MCSP and 71 UC dyads provided sufficient CSRI data to allow costs to be calculated at baseline; and at 6-month follow-up, 83 MCSP dyads and 69 UC dyads. Data on outcome measures were available at both assessment points for 83 MCSP and 71 UC dyads. Costs and outcomes data from 83 MCSP dyads (Italy N=37; Poland $\mathrm{N}=19 ; \mathrm{UK} \mathrm{N}=27$ ) and $69 \mathrm{UC}$ dyads (Italy $\mathrm{N}=20$; Poland $\mathrm{N}=18$; $\mathrm{UK} \mathrm{N}=31$ ) that completed the study were available for cost-effectiveness analyses. Participants in each dyad did not necessarily complete every measure. The number of participants completing any one measure ranged from 77 to 82 in the MCSP group and 62 to 69 in the UC group.

\section{Baseline characteristics}

Groups were comparable in terms of age, sex, educational qualifications and marital status of people with dementia and carers, whether either of the dyad lived alone, and dementia severity (mild, moderate, severe) (Table 1). One case was missing GDS data. We compared the demographic characteristics of dyads that completed the study and those that did not within their allocation group. In the UC group, one statistically significant difference in baseline characteristics was found: people with dementia in completing dyads were almost 4 years younger than those in non-completing dyads (81.9 (SE 1.8) years in 17 non-completers vs. 78.1 (SE 0.6) years in 66 completers; a difference of $-3.8(95 \%$ CI $-7.6,-0.1), p=0.045)$. 


\section{Intervention-related attendances and costs}

Meeting Centres: total attendances, total costs and unit costs of attendance

Most people with dementia in the intervention group used Meeting Centres at least once a week over the 6 months following baseline interview; $42 \%$ visited the centres twice a week. Polish centres averaged $40 \%$ more attendances by people with dementia than UK and $30 \%$ more than Italian centres, but also had the lowest number of carer attendances (supplementary file 3, Table S3.1). UK centres reported more carer attendances than centres in Poland or Italy. Attendances by individuals with dementia lasted approximately 7 hours per day, and carer sessions (see below) lasted 1-to-2 hours.

Total MC costs were highest in the UK and lowest in Poland (supplementary file 3, Table S3.1). Much of this difference is attributable to higher English staff costs (valued at minimum wage). Total costs were split according to distributions of hours spent by centres providing the intervention to carers and people with dementia. Carers' time included time spent at any organised carer event: discussion groups and informative sessions, sessions where carers were active participants in the day club alongside people with dementia and monthly centre meetings. Costs per session for people with dementia and carers were considerably lower in Poland than in the UK or Italy, given that centres in Poland incurred the lowest total costs and the highest number of attendances by people with dementia. The cost per session for a person with dementia across Polish centres $(€ 57.78)$ was $60 \%$ of the cost in the other two countries $(€ 101.70$ in England; €94.59 in Italy). Session costs in the UK and Italy were more comparable: for people with dementia and carers, sessions cost $€ 7.1$ and $€ 8.7$ more in UK than in Italian MCs respectively. 
Meeting Centre Support Programme attendances by research participants

On average, over the first 6 months from baseline interview, people with dementia attended MCSP 45 times (median 44.7; inter-quartile range 27) and carers attended groups 15 times (median 7; inter-quartile range 14) (Table 2). The average perdyad cost (online supplementary file 3, table S3.2) of providing MCSP across three countries over 6 months was $€ 4,703$ ( $95 \%$ CI $€ 4,113$ to $€ 5,294)$. Including out-ofpocket costs of travel (fares and mileage) to centres, the cost was $€ 4,794$ (95\% CI $€ 4,198$ to $€ 5,391)$.

\section{Health, social care and broader societal costs}

Across MCSP and UC groups, numbers of people with dementia using health services were low (online supplementary file 3, Table $\underline{\mathrm{S} 3.3}$ ) apart from outpatient and GP appointments. Most participants reported taking mental health medication for dementia, antipsychotics, antidepressants or anxiolytics (79\% of MCSP and $82 \%$ of UC at baseline; $77 \%$ of MCSP and $78 \%$ of UC at 6 -months). While people with dementia had relatively few contacts with most services over the 3 months prior to each assessment, they received an average of 19 home care visits in the MCSP and 8 home care visits in the UC group at baseline; and they received 22 visits in the MCSP and 7 visits in the UC group at follow-up. Almost all received assistance from close carers and other relatives and friends, amounting to hundreds of hours of unpaid care. Unadjusted health and social care costs of people with dementia (online supplementary file 3, Table S3.2) likewise show that community-based social care (e.g. social worker and home care visits) constituted the largest category of health and social care expenditure in both groups at both assessment points. In the UC group, societal costs at both assessment points were more than twice health and social care costs. Regression estimates of follow-up period costs (Table 3) suggest that total health and social care costs did not 
differ between groups. From a societal perspective, the MCSP group had higher 6month costs (difference of $€ 3,810,95 \%$ CI $€ 381$ to $€ 7,128$ ). Taking MCSP attendance costs into account, the MCSP group's health and social care costs were $€ 5,941$ (95\% CI $€ 3,753$ to $€ 8,264)$ higher than for the UC group; from a societal perspective costs were $€ 8,514(95 \% \mathrm{CI} € 5,078$ to $€ 11,842)$ greater in the MCSP than the UC group.

Missingness was concentrated in what are generally rarely used items with small contributions to total costs (respite care, GP home visits) (Tables S3.2 and S3.3).

\section{Outcomes}

Unadjusted mean EQ-5D, QOL-AD and SSCQ scores did not differ between groups at either baseline or follow-up (supplementary file 3 Table S3.4). At follow-up, MCSP mean scores were higher (i.e. quality of life was better) relative to UC on three DQoL subscales (self-esteem, positive affect, feelings of belonging). Results of outcomes regressions are given in Table 4. Adjusted between-group difference in QALY gain was small and not significant $(0.01,95 \% \mathrm{CI}-0.01$ to 0.02$)$. Mean QOL-AD scores were 1.38 points higher in the MCSP than the UC group (95\% CI -0.02 to 2.71). Carers' sense of competence scores did not differ between groups. On the DQoL, there were betweengroup differences in self-esteem, positive affect, and feelings of belonging, favouring MCSP

\section{Cost-effectiveness analyses}

People with dementia

Very small differences in QALY and large differences in costs meant that the cost per QALY, whether confined to health and social care or including societal costs, was extremely high (Table 5). Probability of cost-effectiveness was zero at the equivalent of 
the lower NICE threshold for adoption into the NHS (£20,000 or $€ 21,800$ per QALY) (National Institute for Health and Care Excellence, 2013) and at willingness-to-pay values of up to $€ 350,000$ (CEAC figure excluded for this reason). The cost of achieving a one-point difference in QOL-AD completed by people with dementia was $€ 4,600$; probability of cost-effectiveness (Figure 1) exceeded 50\% at WTP of $€ 5,000$ from a health and social care perspective and $95 \%$ at WTP of $€ 26,000$. Considering societal costs, probability of cost-effectiveness was $50 \%$ at WTP of $€ 7,000$ per six months and $95 \%$ at $€ 35,000$. For the DQoL positive affect subscale (supplementary file 4 Table S4.1), ICERs were $€ 2,800$ (health and social care perspective) and $€ 4,100$ (societal perspective). A one-point gain in this subscale had a probability of cost-effectiveness (from health and social care perspective) of $99 \%$ at WTP over $€ 8,000$ (online supplementary file 4 Figure S4.3). Results using feelings of belonging and self-esteem subscale measures featured slightly higher ICERs, of $€ 5,500$ each.

Carers

The SSCQ ICER was negative (because UC had a non-significantly higher mean score than MCSP). From either the health and social care or societal perspectives, probability of cost-effectiveness was low (not exceeding 10\%) over a range of WTP up to $€ 50,000$ (Figure 2).

\section{Sensitivity analyses}

Results of sensitivity analyses are given in online supplementary file 2. Cost estimates in most scenarios were similar to those in the main analyses. Results of the maximumcapacity scenario demonstrated that unit cost estimates of MCSP had a substantial impact on overall costs of the intervention: mean per-participant cost of the six-month intervention was less than half the estimate used in the main analysis $(€ 2,094$ vs 
$€ 4,703)$. However, in all scenarios, the cost-effectiveness analysis results were reasonably consistent with those of the main analyses.

\section{Discussion}

Most people with dementia using Meeting Centres attended at least weekly. Quality of life outcomes were better in the MCSP than in the UC group on QOL-AD and three DQoL subscales (positive affect, self-esteem, feelings of belonging). Carers' sense of competence did not differ between groups.

Total mean costs from the health and social care perspective did not differ between groups if intervention costs were excluded but were higher in the MCSP group once included. Not all centres reached maximum capacity in this first implementation period, so MCSP costs per dyad might fall once the programme was fully implemented. A relatively small percentage of UC participants used conventional day care $(21 \%$ at baseline; $16 \%$ at follow-up), and a lower percentage of MCSP participants did the same (14\% at baseline; $11 \%$ at follow-up) (in some cases MCSP participants were already using day care and combined this with the new MCSP service, which also offered support to the carer; for ethical and pragmatic reasons they were not excluded from the intervention group). The limited use of day care in the UC group in this study is in contrast with the original Dutch studies, where all UC participants attended day care.

While cost-utility analyses demonstrated low probability of cost-effectiveness over a range of WTP values up to $€ 350,000$, there was some evidence of costeffectiveness of MCSP compared to UC in terms of dementia-specific quality of life for people with dementia (QOL-AD exceeds $95 \%$ probability of cost-effectiveness at a WTP of $€ 26,000$, DQoL positive affect achieves $99 \%$ probability of cost-effectiveness at a WTP of $€ 8,000)$. The inclusion of QOL-AD and DQoL provides a measure of the impact of MCSP on quality of life for people with dementia. These metrics cover some 
dimensions of health-related quality of life in dementia not covered by EQ-5D (e.g. loss of appetite, restlessness), as well as dimensions of the broader concept of quality of life such as self-esteem and family support (Hounsome, Orrell, \& Edwards, 2011).

Carers' sense of competence did not significantly differ between MCSP and UC groups, while costs were higher. Perhaps the SSCQ was not sufficiently sensitive to the benefits produced by the intervention; carer satisfaction was high (Szcześniak et al., 2019). It may be that only certain aspects of carers' sense of competence improved in response to the practical, emotional and social support (or respite time for the carer) provided by MCs.

The UK had the lowest number of MCSP attendances by people with dementia but the highest number of carer attendances. Such variations in attendance patterns warrant further investigation to understand how local practices influence carer involvement in MCs and carer burden and to tailor the intervention accordingly. One explanation could be cultural and social differences between countries: for instance, in Poland, many carers were working during the day and also some preferred not to engage in the centre activities. There was also between-country variation in total costs. Costs from a societal perspective in the Polish MCSP group were not significantly higher than in the UC group, in contrast with the other two countries. This reflects differences between countries in minimum wage rates used to value unpaid carer inputs.

\section{Strengths and limitations}

The MEETINGDEM project successfully implemented Meeting Centres for people with dementia in the space of a year or less. The project team evaluated the impact of MCSP from multiple perspectives (implementation, user satisfaction, effectiveness and costeffectiveness (Brooker et al., 2018; Evans et al., 2020; Mangiaracina et al., 2017; Szcześniak et al., 2019; Van Mierlo et al., 2018). The cost-effectiveness evaluation 
produced a set of unit costs for MCSP in Italy, Poland and England, and collected detailed information on MCSP attendance by participants with dementia and carers. There were some limitations in data availability collected by the CSRI, particularly in terms of respite care and care from relatives other than the dyadic carer. Data were not available for all cases on some resource use and cost measures. On the other hand, missing data were generally concentrated in relatively seldom-used items such as respite care.

Study design had limitations common to all non-randomised designs: we cannot assume that MCSP and UC groups were comparable on unobserved characteristics (e.g. income levels, activities of daily living, or cognition, although the latter two are arguably captured in the GDS). The two groups appeared similar in terms of observed demographic characteristics and comparable in terms of dementia severity distributions. Analyses controlled for baseline differences in outcomes and costs.

The 6-month follow-up period, while allowing comparisons to the original Dutch study (Dröes, Meiland, et al., 2004), proved relatively short in terms of detecting change in utilisation of high-cost services by people with dementia: e.g. there were relatively few hospital admissions. There were also few nursing home admissions: 10 dyads did not complete the study because the person with dementia had permanently moved to a nursing home. We can only speculate on the possible longer-term costs and outcomes. Over a longer-period, MCs could further embed into communities, and perhaps engage people with mild dementia as early as possible (rather than also accepting people with a more advanced dementia from the start as seen in this study (Brooker et al., 2018)). Combined targeting and access to formal and informal community support networks could in turn reduce centre costs and improve outcomes (e.g. carer stress). 
A minimum clinically important difference has not been established for QOLAD (Holden, Jones, Baker, Boersma, \& Kluger, 2016) and decision-makers may need to consult clinicians to consider whether a one-point difference is sufficiently large to be worth $€ 5,000$ for a 6-month combined support intervention. A similar question will arise in relation to the DQoL subscales.

\section{Implications for policy and practice}

The unit cost of an hour of MCSP attendance was reasonably similar to published estimates of English local authority day care: at approximately $€ 16$ per hour, the cost of the combined MCSP was approximately $20 \%$ higher than that of generic UK day care (€13 per hour (L. Curtis \& Burns, 2015)). While MCs in their first year of operation (and potentially not yet achieving their full capacity) might not appear to be lower-cost alternatives to local government-provided day care, we must remember that the combined MCSP offers tailored post-diagnostic support services for both people with dementia and their carers, while standard day care only offers activities to the former.

Already stretched by demographic and budgetary pressures, long-term care systems in some countries have been further challenged by public expenditure cuts since the 2008 financial crisis. In England, the number of people receiving publicly funded community-based social care support dropped by 30\% between 2005 and 2014 (Humphries, Thorlby, Holder, Hall, \& Charles, 2016). While no official figures are collected on the number of day care centres in England, there is anecdotal evidence of a sharp decline in recent years, despite rapid growth in the number of people with dementia; budgetary pressures have resulted in centres merging and introducing user charges (Needham, 2012). Local and national voluntary organisations may want to consider how to replicate the MCSP approach while maintaining a sustainable funding base. In most countries, mixed funding will be needed to support MCs. In the 
Netherlands, funding is received from local government, long-term care insurance on an individual basis, and sometimes from 'friends of Meeting Centres foundations.' Most MCs participating in this study received funding from local authorities but some were part- or wholly-funded by non-governmental organisations. In some centres, a small proportion of centre income was derived from user charges.

Planners and commissioners should consider all the evidence from the MEETINGDEM study, including effects on other outcomes for people with dementia and carers, user satisfaction and other qualitative and quantitative outcomes not considered in this paper (Brooker et al., 2018; Evans et al., 2020; Szcześniak et al., 2019). The context in which MCs operate is important. Decision-makers should consider that for many people with dementia in Europe there is currently little alternative to home-based social services; indeed, often no formal care services are available.

\section{Acknowledgements}

This was an EU Joint Programme - Neurodegenerative Disease Research (JPND) Project, Grant/Award Number HC-559-018. The work was supported through the following funding organisations under the aegis of JPND: Italy, Ministry of Education and Ministry of Health; the Netherlands, ZonMw; Poland, Narodowe Centrum Badań i Rozwoju; and UK, Economic and Social Research Council, Grant/Award Number: ES/L00920X/1.

\section{References}

Allen, C., \& Beecham, J. (1993). Costing Services: Ideals and Reality. In A. Netten \& J. Beecham (Eds.), Costing Community Care: Theory and Practice. Avebury: Ashgate.

Alzheimer Europe. (2006). Who Cares? The state of dementia care in Europe. Retrieved from Luxembourg: http://www.alzheimereurope.org/content/download/57035/363238/file/Carer $\% 27 \mathrm{~s} \% 20$ Survey $\% 20 \mathrm{FIN}$ AL\%20VERSION.pdf 
Alzheimer Europe. (2014). Dementia in Europe: National care pathways for people with dementia living at home. Retrieved from Luxembourg: http://alzheimereurope.org/content/download/79308/491680/file/dementia\%20in\%20europe $\% 20$ yearbook $\% 202014 . p d f$

Aries, M. J. H., Le Bastard, N., Debruyne, H., Van Buggenhout, M., Nagels, G., De Deyn, P. P., \& Engelborghs, S. (2010). Relation between frontal lobe symptoms and dementia severity within and across diagnostic dementia categories. International Journal of Geriatric Psychiatry, 25(11), 1186-1195. doi:http://dx.doi.org/10.1002/gps.2481

Brod, M., Stewart, A. L., Sands, L., \& Walton, P. (1999). Conceptualization and measurement of quality of life in dementia: the dementia quality of life instrument (DQoL). Gerontologist, 39(1), 25-35. Retrieved from http://www.ncbi.nlm.nih.gov/pubmed/10028768

Brooker, D., Evans, S., Evans, S., Bray, J., Saibene, F. L., Scorolli, C., . . . Droes, R. M. (2018). Evaluation of the implementation of the Meeting Centres Support Program in Italy, Poland, and the UK; exploration of the effects on people with dementia. Int J Geriatr Psychiatry, 33(7), 883-892. doi: https://doi.org/10.1002/gps.4865

Brooks, R. (1996). EuroQol: the current state of play. Health Policy, 37(1), 53-72. doi:https://doi.org/10.1016/0168-8510(96)00822-6

Curtis, L. (2012). Unit Costs of Health and Social Care 2012. Canterbury: Personal Social Services Research Unit, University of Kent.

Curtis, L., \& Burns, A. (2015). Unit Costs of Health and Social Care 2015. Canterbury: Personal Social Services Research Unit, University of Kent.

Dröes, R. M. (1991). In Movement; on psychosocial care for older people with dementia [In Beweging; over psychosociale hulpverlening aan demente ouderen.]. (Academic thesis). Vrije Universiteit Amsterdam. Publ. Intro, Nijkerk.

Dröes, R. M., Breebaart, E., Meiland, F. J., Van Tilburg, W., \& Mellenbergh, G. J. (2004). Effect of Meeting Centres Support Program on feelings of competence of family carers and delay of institutionalization of people with dementia. Aging Ment Health, 8(3), 201-211. doi:https://doi.org/10.1080/13607860410001669732

Dröes, R. M., Meiland, F., Schmitz, M., \& van Tilburg, W. (2004). Effect of combined support for people with dementia and carers versus regular day care on behaviour and mood of persons with dementia: Results from a multi-centre implementation study. . International Journal of Geriatric Psychiatry, 19(7), 673. doi:https://doi.org/10.1002/gps.1142

Dröes, R. M., Meiland, F. J., Evans, S., Brooker, D., Farina, E., Szczesniak, D., . . . Chattat, R. (2017). Comparison of the adaptive implementation and evaluation of the Meeting Centers Support Program for people with dementia and their family carers in Europe; study protocol of the MEETINGDEM project. BMC Geriatr, 17(1), 79. doi:https://doi.org/10.1186/s12877-017-0472-x

Dröes, R. M., Meiland, F. J., Schmitz, M. J., \& Van Tilburg, W. (2006). Effect of the Meeting Centres Support Program on informal carers of people with dementia: results from a multi-centre study. Aging Ment Health, 10(2), 112-124. doi:https://doi.org/10.1080/13607860500310682

Dröes, R. M., Meiland, F. J. M., Schmitz, M., \& Van Tilburg, W. (2011). An evaluation of the Meeting Centres Support Programme among persons with dementia and their carers. Nonpharmacological Therapies in Dementia, 2(1), 19-39 
Dröes, R. M., van der Roest, H. G., van Mierlo, L., \& Meiland, F. J. (2011). Memory problems in dementia: adaptation and coping strategies and psychosocial treatments. Expert Rev Neurother, 11(12), 1769-1781; quiz 1782. doi:https://doi.org/10.1586/ern.11.167

Drummond, M., Sculpher, M. J., Claxton, K., Stoddart, G. L., \& Torrance, G. W. (2015). Methods for the economic evaluation of health care programmes (Fourth edition / Michael F. Drummond, Mark J. Sculpher, Karl Claxton, Greg L. Stoddart, George W. Torrance. ed.).

Evans, S., Evans, S., Brooker, D., Henderson, C., Szcześniak, D., Atkinson, T., .. . Dröes, R. M. (2020). The impact of the implementation of the Dutch combined Meeting Centres Support Programme for family caregivers of people with dementia in Italy, Poland and UK. Aging Ment Health, 24(2), 280-290. doi:https://doi.org/10.1080/13607863.2018.1544207

Faria, R., Weatherly, H., \& van den Berg, B. (2012). A review of approaches to measure and monetarily value informal care. In L. Curtis (Ed.), Unit Costs of Health and Social Care 2012. Canterbury: Personal Social Services Research Unit, University of Kent.

Fields, N. L., Anderson, K. A., \& Dabelko-Schoeny, H. I. (2014). The effectiveness of adult day services for older adults: A review of the literature from 2000 to 2011. Journal of Applied Gerontology, 33(2), 130. Retrieved from http://journals.sagepub.com/doi/10.1177/0733464812443308

Galeotti, F., Giusti, A., Meduri, F., Raschetti, R., Scardetta, P., \& Vanacore, N. (2013). Epidemiological Data on Dementia: Synthesis Report. ALzheimer COoperation Valuation in Europe (ALCOVE). Retrieved from Rome: http://www.alcoveproject.eu/images/synthesis-report/ALCOVE_SYNTHESIS REPORT WP4.pdf

Glick, H. (2007). Economic evaluation in clinical trials. Oxford ; New York: Oxford University Press.

Herdman, M., Gudex, C., Lloyd, A., Janssen, M. F., Kind, P., Parkin, D., . . Badia, X. (2011). Development and preliminary testing of the new five-level version of EQ-5D (EQ-5D-5L). Quality of Life Research, 20(10), 1727-1736. doi:http://dx.doi.org/10.1007/s11136-011-9903-x

HM Treasury. (2003). The Green Book. Appraisal and Evaluation in Central Government. Retrieved from London:

Holden, S. K., Jones, W. E., Baker, K. A., Boersma, I. M., \& Kluger, B. M. (2016). Outcome measures for Parkinson's disease dementia: a systematic review. Movement disorders clinical practice, 3(1), 9-18. doi:https://doi.org/10.1002/mdc3.12225

Hounsome, N., Orrell, M., \& Edwards, R. T. (2011). EQ-5D as a quality of life measure in people with dementia and their carers: evidence and key issues. Value Health, 14(2), 390-399. doi:https://doi.org/10.1016/j.jval.2010.08.002

Humphries, R., Thorlby, R., Holder, H., Hall, P., \& Charles, A. (2016). Social care for older people. Home truths.

Janssen, M. F., Pickard, A. S., Golicki, D., Gudex, C., Niewada, M., Scalone, L., . . . Busschbach, J. (2013). Measurement properties of the EQ-5D-5L compared to the EQ-5D-3L across eight patient groups: a multi-country study. Quality of Life Research, 22(7), 1717-1727. doi:http://dx.doi.org/10.1007/s11136-012-0322-4

Jowett, S., Bryan, S., Poller, L., van den Besselaar, A. M. H. P., van der Meer, F. J. M., Palareti, G., . . Jespersen, J. (2009). The cost-effectiveness of computerassisted anticoagulant dosage: results from the European Action on Anticoagulation (EAA) multicentre study. Journal of Thrombosis and 
Haemostasis, 7(9), 1482-1490. doi: https://doi.org/10.1111/j.1538-

7836.2009.03508.x

Knapp, M., Iemmi, V., \& Romeo, R. (2013). Dementia care costs and outcomes: a systematic review. Int J Geriatr Psychiatry, 28(6), 551-561.

doi:10.1002/gps.3864

Koopmanschap, M. A., van Exel, J. N., van den Berg, B., \& Brouwer, W. B. (2008). An overview of methods and applications to value informal care in economic evaluations of healthcare. Pharmacoeconomics, 26(4), 269-280. Retrieved from http://www.ncbi.nlm.nih.gov/entrez/query.fcgi?cmd=Retrieve \&db=PubMed\&do $\mathrm{pt}=$ Citation\&list_uids $=18370563$

Logsdon, R. G., Gibbons, L. E., McCurry, S. M., \& Teri, L. (2002). Assessing quality of life in older adults with cognitive impairment. Psychosom Med, 64(3), 510519. Retrieved from http://www.ncbi.nlm.nih.gov/pubmed/12021425

Mangiaracina, F., Chattat, R., Farina, E., Saibene, F. L., Gamberini, G., Brooker, D., . . . Meiland, F. J. M. (2017). Not re-inventing the wheel: the adaptive implementation of the meeting centres support programme in four European countries. Aging \& Mental Health, 21(1), 40-48. doi:https://doi.org/10.1080/13607863.2016.1258540

Manthorpe, J., \& Moriarty, J. (2014). Examining day centre provision for older people in the UK using the Equality Act 2010: findings of a scoping review. Health Soc Care Community, 22(4), 352-360. doi:https://doi.org/10.1111/hsc.12065

National Institute for Health and Care Excellence. (2013). Guide to the methods of technology appraisal. Retrieved from London:

https://www.nice.org.uk/article/pmg9/resources/non-guidance-guide-to-themethods-of-technology-appraisal-2013-pdf

National Institute for Health and Care Excellence. (2018). Position statement on use of the EQ-5D-5L valuation set for England (updated November 2018). Retrieved from https://www.nice.org.uk/about/what-we-do/our-programmes/niceguidance/technology-appraisal-guidance/eq-5d-51

Needham, C. (2012). What is happening to day centre services? Voices from frontline staff. Retrieved from Birmingham:

http://www.birmingham.ac.uk/Documents/college-social-sciences/socialpolicy/HSMC/publications/2012/what-is-happening-to-day-centre-servicesUnison-report.pdf

OECD. (2017). PPPs and exchange rates. Purchasing power parities for GDP, national currency per US dollar. In Organisation for Economic Co-operation and Development (Ed.).

Patel, A., McCrone, P., Leese, M., Amaddeo, F., Tansella, M., Kilian, R., . . Knapp, M. (2013). Cost-effectiveness of adherence therapy versus health education for people with schizophrenia: randomised controlled trial in four European countries. Cost Eff Resour Alloc, 11(1), 12. doi:https://doi.org/10.1186/14787547-11-12

Szcześniak, D., Rymaszewska, J., Saibene, F. L., Lion, K. M., D’arma, A., Brooker, D., ... Farina, E. (2019). Meeting centres support programme highly appreciated by people with dementia and carers: a European cross-country evaluation. Aging \& Mental Health, 1-11. doi:https://doi.org/10.1080/13607863.2019.1683814

Tretteteig, S., Vatne, S., \& Rokstad, A. M. M. (2016). The influence of day care centres for people with dementia on family caregivers: an integrative review of the literature. Aging \& Mental Health, 20(5), 450-462. doi:http://dx.doi.org/10.1080/13607863.2015.1023765 
van Hout, B., Janssen, M. F., Feng, Y.-S., Kohlmann, T., Busschbach, J., Golicki, D., . . . Pickard, A. S. (2012). Interim Scoring for the EQ-5D-5L: Mapping the EQ-5D5L to EQ-5D-3L Value Sets. Value in Health, 15(5), 708-715.

doi:https://doi.org/10.1016/j.jval.2012.02.008

Van Mierlo, L. D., Chattat, R., Evans, S., Brooker, D., Saibene, F. L., Gamberini, G., . . . Meiland, F. J. M. (2018). Facilitators and barriers to adaptive implementation of the Meeting Centers Support Program (MCSP) in three European countries; the process evaluation within the MEETINGDEM study. International Psychogeriatrics, 30(4), 527-537. doi:https://doi.org/10.1017/S1041610217001922

Vernooij-Dassen, M. J., Felling, A. J., Brummelkamp, E., Dauzenberg, M. G., van den Bos, G. A., \& Grol, R. (1999). Assessment of caregiver's competence in dealing with the burden of caregiving for a dementia patient: a Short Sense of Competence Questionnaire (SSCQ) suitable for clinical practice. $J$ Am Geriatr Soc, 47(2), 256-257. doi: https://doi.org/10.1111/j.1532-5415.1999.tb04588.x

Wittenberg, R., Knapp, M., Hu, B., Comas-Herrera, A., King, D., Rehill, A., . . . Kingston, A. (2019). The costs of dementia in England. International Journal of Geriatric Psychiatry, 34(7), 1095-1103. doi:https://doi.org/10.1002/gps.5113 


\section{Tables}

Table 1. Baseline characteristics of person with dementia and carer dyads in MCSP and UC for individuals with economic and outcomes data available at baseline and 6-month follow-up.

\begin{tabular}{|c|c|c|c|c|}
\hline \multirow[t]{2}{*}{ 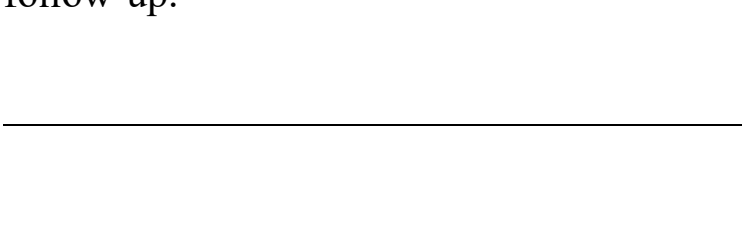 } & \multicolumn{2}{|c|}{$\begin{array}{l}\text { MCSP } \\
(\mathrm{N}=83) \\
\end{array}$} & \multicolumn{2}{|c|}{$\begin{array}{l}\mathrm{UC} \\
(\mathrm{N}=69)\end{array}$} \\
\hline & $\mathbf{N}$ & $\begin{array}{l}\text { Mean (SD) } \\
\text { or } \%\end{array}$ & $\mathbf{N}$ & $\begin{array}{l}\text { Mean (SD) } \\
\text { or \% }\end{array}$ \\
\hline \multicolumn{5}{|l|}{ Person with dementia } \\
\hline Age & 81 & $78.2(7.8)$ & 64 & $78.1(7.2)$ \\
\hline Lives alone & 22 & 27 & 11 & 16 \\
\hline Female & 48 & 58 & 39 & 57 \\
\hline \multicolumn{5}{|l|}{ Marital status } \\
\hline Married/cohabiting/civil partners & 47 & 57 & 42 & 64 \\
\hline Widowed & 32 & 39 & 18 & 27 \\
\hline Separated/divorced & 1 & 1 & 3 & 5 \\
\hline Single/never married & 3 & 4 & 3 & 4 \\
\hline \multicolumn{5}{|l|}{ Level of education } \\
\hline Level 1/no qualifications & 23 & 28 & 22 & 33 \\
\hline GCSE A-level/equivalent & 36 & 44 & 35 & 53 \\
\hline Graduate education & 23 & 28 & 9 & 14 \\
\hline \multicolumn{5}{|l|}{ Severity of dementia } \\
\hline No-to-mild (<=3 GDS) & 27 & 33 & 23 & 34 \\
\hline Moderate-moderately severe (4-5 GDS) & 51 & 61 & 42 & 62 \\
\hline Severe-very severe (6-7 GDS) & 5 & 6 & 3 & 4 \\
\hline \multicolumn{5}{|l|}{ Carer } \\
\hline Age & 82 & $63.5(13.3)$ & 66 & $63.0(14.1)$ \\
\hline Lives alone & 4 & 6 & 5 & 8 \\
\hline Female & 62 & 75 & 47 & 68 \\
\hline \multicolumn{5}{|l|}{ Marital status } \\
\hline Married/cohabiting/civil partners & 69 & 84 & 52 & 76 \\
\hline Widowed & 0 & 0 & 2 & 3 \\
\hline Separated/divorced & 5 & 6 & 2 & 3 \\
\hline Single/never married & 8 & 10 & 12 & 18 \\
\hline \multicolumn{5}{|l|}{ Level of education } \\
\hline Level $1 /$ no qualifications & 9 & 11 & 13 & 19 \\
\hline GCSE A-level/equivalent & 43 & 52 & 30 & 45 \\
\hline Graduate education & 30 & 37 & 25 & 37 \\
\hline \multicolumn{5}{|l|}{ Relationship to person with dementia } \\
\hline Spouse or Partner & 43 & 52 & 38 & 55 \\
\hline Siblings, child, other relations inc.in-laws & 40 & 48 & 31 & 45 \\
\hline
\end{tabular}

Note: GDS=Global Deterioration Scale 
Table 2. MCSP attendance data in the 6 months after baseline interview, complete dyads of research participants with economic data available at baseline and follow-up

\begin{tabular}{lllllll}
\hline Italy, Poland and UK & Mean & SE & Min & Max & IQR & N \\
& & & & & & \\
\hline Person with dementia - days attended MC & 44.71 & 1.91 & 5 & 71 & 27 & 83 \\
Carer - Informative meeting attendances & 2.47 & 0.6 & 0 & 31 & 2 & 83 \\
Carer - All other carer meeting attendances & 4.57 & 0.82 & 0 & 31 & 5 & 83 \\
Carer - active participation at MC attendances & 2.81 & 0.8 & 0 & 36 & 0 & 83 \\
Carer - Discussion group attendances & 5.59 & 0.85 & 0 & 38 & 8 & 83 \\
Carer attendances, all groups & 15.43 & 2.59 & 0 & 132 & 14 & 83 \\
\hline
\end{tabular}

Note: $\mathrm{IQR}=$ interquartile range 
Table 3. Adjusted health and social care and unpaid carer costs with bootstrapped confidence intervals (PPP-adjusted $€$ ) over 6-month follow-up, in the sample with economic data available at baseline and 6 month follow-up in dyads completing the study $(\mathrm{N}=152)$

\begin{tabular}{|c|c|c|c|c|c|c|c|c|c|}
\hline Cost category ${ }^{a}$ & $\mathbf{N}$ & $\begin{array}{l}\text { MCSP } \\
\operatorname{Mean}(€)^{\natural}\end{array}$ & $95 \% \mathrm{CI}^{\mathrm{b}}$ & $\mathbf{N}$ & $\begin{array}{l}\text { Usual } \\
\text { Care } \\
\text { Mean(€) } \\
\end{array}$ & $95 \% \mathrm{CI}^{\mathrm{b}}$ & $\begin{array}{l}\text { Mean } \\
\text { difference } \\
(€): \text { MCSP-UC }^{\mathrm{b}} \\
\end{array}$ & $95 \% \mathrm{CI}^{\mathrm{b}}$ & $\begin{array}{l}\text { p- } \\
\text { value }\end{array}$ \\
\hline Hospital & 83 & 1,120 & 491 to 1,994 & 67 & 980 & 465 to 1,740 & 141 & -863 to 1,239 & 0.79 \\
\hline Primary and community health & 83 & 249 & 189 to 318 & 68 & 370 & 293 to 471 & -120 & -239 to -20 & $\mathbf{0 . 0 3}$ \\
\hline Respite in care home $\mathrm{c}^{\mathrm{c}}$ & 59 & 0 & 0 & 38 & 0 & 0 & 0 & 0 & - \\
\hline Community-based social care & 83 & 4,119 & 2611 to 6,508 & 68 & 2397 & 1,155 to 4,142 & 1,722 & -75 to 4,133 & 0.10 \\
\hline Community mental health & 83 & 156 & 70 to 311 & 68 & 76 & 23 to 171 & 80 & -41 to 259 & 0.29 \\
\hline Day care services & 83 & 253 & 54 to 630 & 68 & 847 & 415 to 1,566 & -594 & $-1,323$ to -160 & 0.03 \\
\hline Equipment and adaptations & 73 & 0 & 0 & 59 & 0 & 0 & 0 & 0 & - \\
\hline Community-based supports & 83 & 223 & 115 to 357 & 68 & 269 & 153 to 433 & -46 & -218 to 97 & 0.56 \\
\hline Medications & 83 & 158 & 108 to 227 & 68 & 152 & 102 to 219 & 6 & -35 to 46 & 0.65 \\
\hline Health \& social care & 83 & 6,015 & 4,243 to 8,284 & 68 & 4,626 & 3,223 to 6,348 & 1,389 & -745 to 3,694 & 0.22 \\
\hline Health \& social care inc. MCSP & 83 & 10,650 & 8,758 to 12,943 & 68 & 4,709 & 3,285 to 6,454 & 5,941 & 3,753 to 8,264 & $\mathbf{0 . 0 0}$ \\
\hline Unpaid care and support ${ }^{d}$ & 83 & 13,546 & 11,351 to 15,765 & 68 & 12,327 & 10,133 to 14,714 & 1,220 & $-1,326$ to 3,712 & 0.34 \\
\hline Societal $^{\mathrm{e}}$ & 83 & 20,102 & 17,244 to 23,068 & 68 & 16,292 & 13,581 to 19,144 & 3,810 & 381 to 7,128 & 0.03 \\
\hline Societal inc. MCSP ${ }^{f}$ & 83 & 24,856 & 21,998 to 27,806 & 68 & 16,342 & 13,654 to 19,195 & 8,514 & 5,078 to 11,842 & 0.00 \\
\hline
\end{tabular}

a Cost of resources over prior 3 months as reported in the CSRI multiplied by 2 to estimate 6-month costs

$\mathrm{b}$ Estimates of costs models adjusted for allocation group, country, baseline severity of dementia and baseline cost; bias-corrected confidence intervals from 12,000 bootstrap replications with replacement. Group means are estimated marginal means. 1 case had no data on baseline GDS (dementia severity) c Adjusted for allocation group, country, baseline severity of dementia only as there was no use of care homes in the UC group at baseline

d Unpaid carer time, lost production, travel expenditure, privately purchased equipment; time valued at minimum wage

e Sum of health and social care costs, unpaid care and support (includes unpaid carer time, lost production, travel expenditure, privately purchased equipment; time valued at minimum wage)

f Sum of health and social care costs, unpaid care and support (includes unpaid carer time, lost production, travel expenditure, privately purchased equipment; time valued at minimum wage) and $\mathrm{MC}$ cost including travel expenditure 
Table 4. Adjusted means for outcome measures at 6-month follow-up with bootstrapped standard errors

\begin{tabular}{|c|c|c|c|c|c|c|c|c|c|}
\hline Outcome measure & $\mathbf{N}$ & $\begin{array}{l}\text { MCSP } \\
\text { Mean }^{\mathrm{a}}\end{array}$ & $95 \% \mathrm{CI}^{\mathrm{a}}$ & $\mathbf{N}$ & $\begin{array}{l}\text { Usual Care } \\
\text { Mean }^{\mathrm{a}}\end{array}$ & $95 \% \mathrm{CI}^{\mathrm{a}}$ & $\begin{array}{l}\text { Mean } \\
\text { difference: } \\
\text { MC-UC }\end{array}$ & $95 \% \mathrm{CI}^{\mathrm{a}}$ & p-value \\
\hline \multicolumn{10}{|l|}{ Person with dementia } \\
\hline QALY & 82 & 0.40 & 0.35 to 0.39 & 65 & 0.40 & 0.34 to 0.38 & 0.01 & -0.01 to 0.02 & 0.36 \\
\hline QOL-AD & 80 & 35.58 & 34.48 to 36.58 & 66 & 34.20 & 33.05 to 35.37 & 1.38 & -0.02 to 2.71 & 0.05 \\
\hline DQoL: Sense of Aesthetics & 81 & 19.29 & 18.24 to 20.41 & 68 & 18.69 & 17.44 to 19.60 & 0.60 & -0.88 to 2.0 & 0.34 \\
\hline DQoL: Self-esteem & 77 & 14.08 & 13.39 to 14.70 & 64 & 13.02 & 12.22 to 13.81 & 1.06 & 0.09 to 2.0 & $\mathbf{0 . 0 3}$ \\
\hline DQoL: Positive affect & 79 & 22.09 & 21.22 to 22.90 & 66 & 19.96 & 19.12 to 20.81 & 2.13 & 1.04 to 3.19 & $\mathbf{0 . 0 0}$ \\
\hline DQoL: Negative affect & 78 & 26.61 & 25.25 to 27.96 & 66 & 25.52 & 23.80 to 26.16 & 1.08 & -0.48 to 2.74 & 0.19 \\
\hline DQoL: Feelings of belonging & 78 & 11.44 & 10.91 to 11.93 & 62 & 10.37 & 9.66 to 11.07 & 1.07 & 0.24 to 1.86 & 0.01 \\
\hline \multicolumn{10}{|l|}{ Carer } \\
\hline SSCQ & 79 & 3.96 & 3.37 to 4.32 & 66 & 4.23 & 3.89 to 4.70 & -0.27 & -0.97 to 0.14 & 0.31 \\
\hline
\end{tabular}

a Estimates of outcomes models adjusted for allocation group, country, and allocation-country interaction term, baseline severity of dementia and baseline outcome; bias-corrected standard errors from 12,000 bootstrap replications with replacement. Group means are estimated marginal means. One case had no data on baseline GDS (dementia severity) 
Table 5. Costs and ICER (PPP-adjusted $€$ ) for MCSP over UC, from health and social care and societal perspectives using complete dyads with main outcome (QALY, QOL-AD, SSCQ) and economic data available at baseline and 6 month follow-up

\begin{tabular}{|c|c|c|c|}
\hline Difference/ICER & $\begin{array}{l}\text { QALY }^{a} \\
(95 \% \text { CI }) \\
\mathrm{N}=147\end{array}$ & $\begin{array}{l}\text { QOL-AD } \\
(95 \% \mathrm{CI}) \\
\mathrm{N}=146\end{array}$ & $\begin{array}{l}\mathrm{SSCQ}^{\mathrm{bc}} \\
(95 \% \mathrm{CI}) \\
\mathrm{N}=145\end{array}$ \\
\hline \multicolumn{4}{|c|}{ Person with dementia } \\
\hline \multicolumn{4}{|c|}{ Health and social care incl. MCSP } \\
\hline Cost difference & $6,094(3,805$ to 8,383$)$ & $6,479(4,342$ to 8,980$)$ & - \\
\hline ICER $^{\mathrm{d}}$ & 832,636 & $4,600(2,000$ to 147,600$)$ & - \\
\hline \multicolumn{4}{|l|}{ Societal ${ }^{e}$} \\
\hline Cost difference & $8,817(5,440$ to 12,194$)$ & $9,070(5,697$ to 12,614$)$ & - \\
\hline ICER $^{\mathrm{d}}$ & $1,204,751$ & $6,500(2,800$ to 204,100$)$ & - \\
\hline \multicolumn{4}{|l|}{ Carer } \\
\hline \multicolumn{4}{|c|}{ Health and social care incl. MCSP } \\
\hline Cost difference & - & - & $6,294 \quad(3,894$ to 88,834$)$ \\
\hline ICER $^{\mathrm{d}}$ & - & - & $-22,900(-7,100$ to 24,600$)$ \\
\hline \multicolumn{4}{|l|}{ Societal } \\
\hline Cost difference & - & - & $8,888 \quad(5,226$ to 12,418$)$ \\
\hline ICER $^{\mathrm{d}}$ & - & - & $-32,600(36,100$ to $-9,800)$ \\
\hline
\end{tabular}

a. ICER: the cost of achieving a QALY gain

b. ICER: cost of achieving a 1-point difference between groups at follow-up on the measure

c. ICERs are negative as MC had lower mean score on this outcome than UC

d. Results rounded to nearest PPP-adjusted $€ 100$

e. sum of health and social care costs, unpaid care and support (includes unpaid carer time, lost production, travel expenditure, privately purchased equipment; time valued at minimum wage) and $\mathrm{MC}$ cost including travel expenditure 


\section{Figures}

Figure 1. Probability of cost-effectiveness: QOL-AD

Figure 2. Probability of cost-effectiveness: SSCQ 